\title{
First report of Curvularia verruculosa causing leaf spot disease of grape (Vitis vinifera) in Afghanistan
}

\author{
Nasir Ahmed Rajput ${ }^{1,2} \cdot$ Hussainullah $^{2,3} \cdot$ Chao Huo $^{1} \cdot \mathrm{JiFen}^{\mathrm{Cao}}{ }^{1} \cdot$ Muhammad Atiq $^{2} \cdot$ Rana Muhammad Atif ${ }^{4}$. \\ Abdul Mubeen Lodhi ${ }^{5} \cdot$ Rehana Naz Syed $^{5} \cdot$ Sohaib Sarfraz $^{2} \cdot$ Akhtar Hameed $^{2} \cdot$ Zhijian Zhao $^{1}$
}

Received: 13 October 2019 / Accepted: 25 July 2020 / Published online: 5 August 2020

(C) Società Italiana di Patologia Vegetale (S.I.Pa.V.) 2020

Keywords Vitis vinifera $\cdot$ leaf spot $\cdot$ Curvularia verruculosa $\cdot$ Afghanistan

Recently, grapevines at Kunar province of Afghanistan have been found severely affected by a new foliar disease. Small brown spots of different shapes were developed on the leaves, these lesions increased in size $(0.5-0.8 \mathrm{~cm}$ diameter $)$ and covered the entire field. Affected leave tissues were surface disinfected, cultured on potato dextrose agar (PDA) plates, and incubated 4 to 5 days at $28^{\circ} \mathrm{C}$, the emerging fungal colonies were purified by hyphal tip method on new PDA plates. Consistently isolated pathogen was recognized as Curvularia verruculosa (Ellis 1966). It produced flattened grayish color colony on PDA medium and black pigmentation on back side of the plate. The hyphae were smooth walled, subhyaline, septate and branched; conidiophores septate macronematous or mononematous, rarely branched, erect or curved, light brown, geniculate close to the apex. Conidia were curved, straight or ellipsoidal, three septa, round from both ends, with verrucolose walls, 24-31 to 10-15 $\mu \mathrm{m}$, light to dark brown, multicellular, the middle third cell larger and darker than other three remaining cells. For molecular characterization, the ITS and the large subunit of the nuclear ribosomal DNA (LSU) were amplified and sequenced with the primers ITS-1/ITS-4

Zhijian Zhao

zhijianzhao@hotmail.com

1 Yunnan Academy of Agricultural Sciences, Industrial Crops Institute, Kunming, China

2 Department of Plant Pathology, University of Agriculture, Faisalabad, Pakistan

3 Ministry of Rural Rehabilitation and Development, Kabul, Afghanistan

4 Department of Plant Breeding and Genetics / USPCAS-AFS, University of Agriculture, Faisalabad, Pakistan

5 Faculty of Plant Protection, Sindh Agriculture University, Tandojam, Pakistan and NL1/NL4, respectively. Sequences were deposited in GenBank (ITS, MF568070 and LSU, MF568071) and shared 99\% similarity (ITS, KP698724 and LSU, KM243295) sequences of $C$. verruculosa present in GenBank. For pathogenicity, ten fresh and symptomless leaves were inoculated with conidial suspension $\left(10^{6}\right.$ spores $\left./ \mathrm{ml}\right)$ on the abaxial surface of the right side and left side with sterile distilled water (SDW) as control. After 7 days of inoculation, typical brown spots appeared on the pathogen inoculated side of leaves, whereas SDW remained symptomless. This pathogen also caused leaf spot disease on Cynodon sp. (Huang et al. 2005). To our knowledge, this is the first report of C. verruculosa causing leaf spot on grapes in the Afghanistan.

\section{References}

Ellis MB (1966) Dematiaceous hyphomycetes. VII. Curvularia, Brachysporium, etc. Mycol Pap 106:1-57

Huang J, Zheng L, Hsiang T (2005) First report of leaf spot caused by Curvularia verruculosa on Cynodon sp. in Hubei, China. Plant Pathol 54:253

Publisher's note Springer Nature remains neutral with regard to jurisdictional claims in published maps and institutional affiliations. 